\title{
Locomotion and postural behaviour
}

\author{
M. Schmidt \\ Institut für Spezielle Zoologie und Evolutionsbiologie, Friedrich-Schiller-Universität Jena, \\ Erbertstr. 1, 07743 Jena, Germany
}

Received: 22 January 2010 - Revised: 10 October 2010 - Accepted: 20 March 2011 - Published: 30 May 2011

\begin{abstract}
The purpose of this article is to provide a survey of the diversity of primate locomotor behaviour for people who are involved in research using laboratory primates. The main locomotor modes displayed by primates are introduced with reference to some general morphological adaptations. The relationships between locomotor behaviour and body size, habitat structure and behavioural context will be illustrated because these factors are important determinants of the evolutionary diversity of primate locomotor activities. They also induce the high individual plasticity of the locomotor behaviour for which primates are well known. The article also provides a short overview of the preferred locomotor activities in the various primate families. A more detailed description of locomotor preferences for some of the most common laboratory primates is included which also contains information about substrate preferences and daily locomotor activities which might useful for laboratory practice. Finally, practical implications for primate husbandry and cage design are provided emphasizing the positive impact of physical activity on health and psychological well-being of primates in captivity.
\end{abstract}

\section{Introduction}

The impression most people have of primate activities is perhaps best expressed by Jack T. Stern and Charles E. Oxnard in the first sentence of their monograph on primate locomotion (Stern and Oxnard, 1973, p. 1): "Primates stand, sit, lie, walk, run, hop, leap, climb, hang, swing, swim, and engage in other activities too numerous to mention. They may do these things often or rarely, quickly or slowly, with agility or clumsiness, on the ground or in the trees (or, with swimming, in the water), on thick branches or thin ones, on vertical, oblique or horizontal supports, with all appendages or only some." Indeed, among mammals, the order primates is practically unique with respect to its broad spectrum of locomotory and non-locomotory behaviours. The latter comprise all the activities and movements related to food acquisition, social behaviour and communication, object manipulation, etc. Clearly, the locomotor apparatus has multiple functions and is therefore better termed motion apparatus.

There are a few factors that have remained constant throughout the evolutionary history of the primate motion system, the first being that primates have always retained a strong tie with the arboreal environment. Even terrestrial species such as baboons, patas monkeys and some macaques spend a considerable time in trees when resting or search-

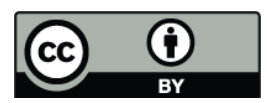

Correspondence to: M. Schmidt (schmidt.manuela@uni-jena.de) ing and consuming food. On the species level, only human beings have successfully forsaken the arboreal habitat and have become the most strictly terrestrial primate species. The majority of primates inhabit arboreal environments in which the supports of locomotion are highly discontinuous, irregular and often instable. Depending on body size, primates have developed a suite of strategies to cope with the particular challenges of arboreal locomotion. Their locomotor adaptations are directed towards providing balance and compliance, stability and mobility, speed and cautiousness in a three-dimensional environment.

The second constant is that primates have never become highly adapted to specific functions but have always maintained great flexibility and adaptability in their behavioural responses to the changing conditions of their environment. They were only able to do so by retaining a relatively unspecialized musculoskeletal system. Primates retained many features ancestral to mammals in general; they have five digits on hands and feet, for example, a clavicle, and unfused forearm bones permitting the pronation and supination of the hand. The anatomical features that distinguish the motion system of primates from that of other mammals are the result of subtle changes in the shape and proportions of homologous elements rather than fundamental rearrangements, losses or additions of body parts (Fleagle, 1999). Adaptive differences among primates mainly concern the lengths of the limbs relative to each other or to body length, tail elongation or reduction and subtle changes in the size and shape of joints. 


\section{Glossary}

Allometry: non-linear relationship between the size of a body part and and the size or mass of the body.

Atelidae: a family of New World monkeys that comprises the spider monkeys (genus Ateles), woolly monkeys (genus Lagothrix), woolly spider monkeys (genus Brachyteles) and the howler monkeys (genus Alouatta).

Cercopithecinae: a subfamily of Old World monkeys that comprises guenons and allies, baboons and allies, mangabeys, and macaques.

Contralateral: located on different sides of the body (e.g. right hand and left foot).

Dorsal: referring to the upper (back) side of the body.

Hominoidea: a superfamily that comprises the families Hylobatidae (gibbons) and Hominidae (including orang-utans, gorillas, chimpanzees, bonobos, and humans).

Homologous: similarity of a particular structure or trait in different species based on common descent.

Intermembral index: calculated as the length of the forelimb long bones (humerus + radius) divided by the length of the hindlimb long bones (femur + tibia) $\times 100$.

Ipsilateral: located on the same side of the body (e.g. right arm and right leg).

Isometry: a change in the size of structures, either during individual growth or over evolutionary timescales, does not lead to changes in proportion.

Kinetic energy: energy $(E)$ of a moving body, defined as the amount of work needed to accelerate a mass $(m$, in $\mathrm{kg})$ from 0 to the current velocity ( $v$, in $\mathrm{m} \mathrm{s}^{-1}$ ), $E=1 / 2 \mathrm{~m} \mathrm{v}^{2}$.

Morphotype: a typus but not a real specimen or species; it serves to centralize typical morphological features of a group of organisms, for example of all leaping primates or of all quadrupeds.

\section{Orthograde: upright}

Pivot: the ankle that connects a limb with the body.

Prehensile: being capable of grasping or holding.

Pronograde: longitudinal axis of the body parallel to the ground.

Sagittal: an imaginary plane that divides the body into a right and a left half.

Ventral: referring to the abdominal side of the body.

Volar skin: skin on the inner side of hands and lower side of feet covered with dermatoglyphs, i.e. a ridged skin.

While the locomotor behaviour of many primate species is well documented and its evolutionary history widely understood, this is not so for non-locomotory activities. Prost (1965) was the first to argue for greater emphasis on postural activities, proposing the terms "positional behaviour" for both locomotion (= a gross displacement of the animal) and postural behaviour, (= no significant displacement of the animal). However, postures only form a minor part of the activities performed by a primate besides locomotion. Over the past years, some effort has been made to find an ordering system for postural behaviours (Fontaine, 1990; Hunt et al.,
1996) but other activities have hardly been considered (Ripley, 1967; Rose, 1977). Therefore, neither the evolutionary history of non-locomotory behaviours nor the potential relationship between morphology and these kinds of motor function have yet been investigated in any kind of detail. This article is dedicated to locomotor behaviour because this is what we know most about, but caution is called for lest locomotion be understood as the only important function shaping the motion system of primates in evolution.

\section{Locomotor modes of primates}

Classifications of locomotor behaviour have occupied generations of scientists over the last century (Ashton and Oxnard, 1964; Mollison, 1910; Napier and Napier, 1967; Napier and Walker, 1967; Rollinson and Martin, 1981; Rose, 1973; Hunt et al., 1996). Both the most influential and the most controversial classification was proposed by Napier and Napier (1967), who divided the spectrum of primate locomotor modes into four discrete categories: quadrupedalism, vertical clinging and leaping, brachiation, and bipedalism. The categories "quadrupedalism" and "brachiation" were each subdivided again according to substrate preferences or taxonomic aspects. The aim of this classification was to find discrete behavioural categories which could be assigned to a particular morphotype with the primary intention of reconstructing the behaviours of fossil species mostly known only from fragmented bone material. Napier and Napier (1967) regarded the function of their locomotor classification to be the same as that of any system of biological classification, namely to categorise information about a group of organisms and permit the recovery of this information by means of a morphotype established for each category. However, the morphology-based nature of their classification gave rise to criticism, mainly from field researchers. The major problem was and remains that a clear linear relationship between behaviour and skeletal morphology does not normally exist in either extant or extinct primates for the simple reason that almost all living primate species display a variety of locomotor behaviours - some for travel, some for foraging and others for escape. We do not know whether morphological adaptations are related to the most frequent and preferred modes or to the most "serious" ones, those modes of locomotion which are only used in critical situations where the animal's motion system is subject to maximum stress (Martin, 1990).

Nevertheless, the traditional classifications still provide a useful framework for the description of locomotor modes, even if some authors call for closer differentiation between behavioural categories (Fontaine, 1990; Hunt et al., 1996; Walker, 1998). The flipside of establishing more and more sub-types and categories, however, is that we risk losing the ability to communicate about these things, at least with people outside the research community. 
A. arboreal walking

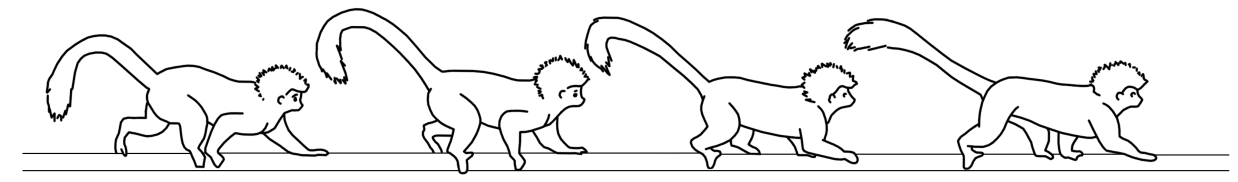

B. terrestrial walking

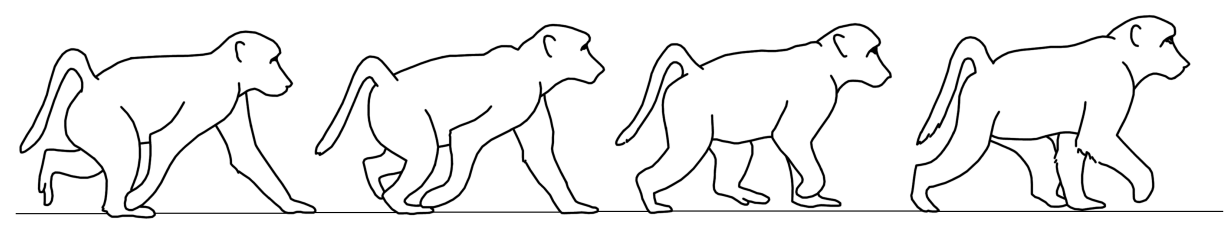

C. knuckle walking

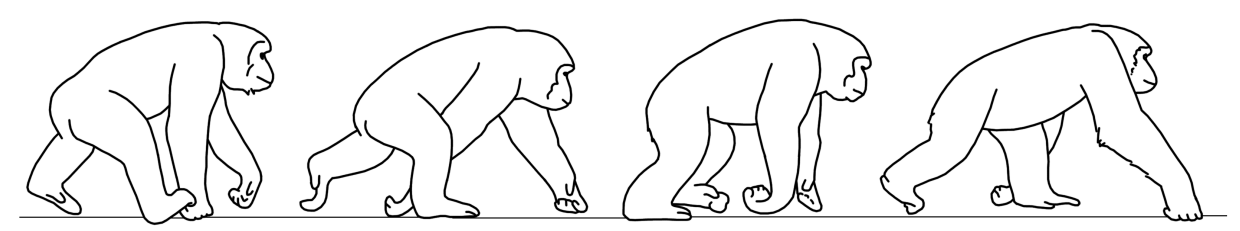

D. bounding

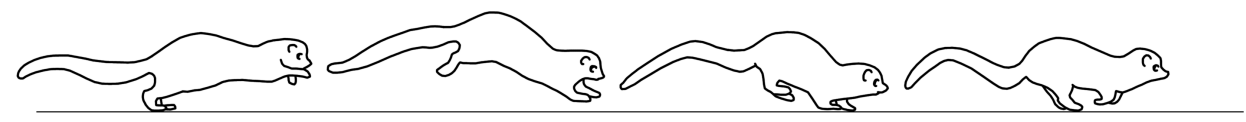

\section{E. galloping}

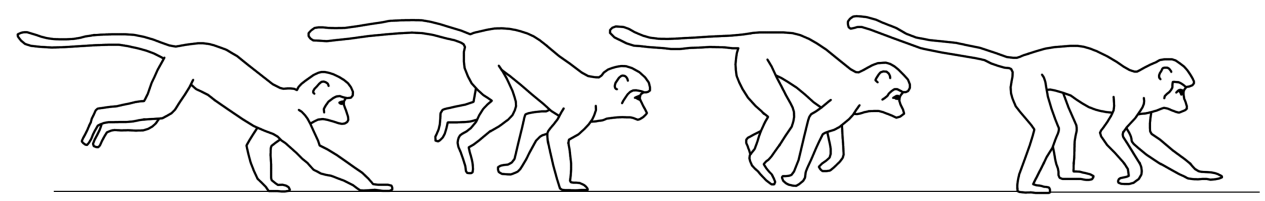

Figure 1. Quadrupedalism in primates. Symmetrical (A, B, C) and asymmetrical (D, E) gaits. (A) arboreal walking (cotton-top tamarin, Saguinus oedipus). (B) terrestrial walking (chacma baboon, Papio ursinus, drawn from Muybridge (1957)). (C) knuckle walking (chimpanzee, Pan troglodytes, drawn after Larson (1998)). (D) bounding (fat-tailed dwarf lemur, Cheirogaleus medius, drawn from Preuschoft et al. (1995)). (E) galloping (vervet monkey, Chlorocebus aethiops, drawn after Larson and Stern (1989)).

For the purposes of a basic introduction to primate biology, the clearest and most practicable way of informing the reader about behavioural diversity in primates seems to be to differentiate between the five main types of locomotor behaviour. These are quadrupedalism, climbing, leaping, suspension and bipedalism. Each of these categories contains various sub-types, some of which are specialized modes of locomotion only practised by a small number of primate species. Specialized locomotor modes often have a phylogenetic component reflected in heritable morphological adaptations such as a specialized anatomy of the foot, the wrist or the shoulder.

\subsection{Quadrupedal walking and running}

Quadrupedal walking and running is basically subdivided into arboreal and terrestrial quadrupedalism. Arboreal quadrupedalism - progression on small supports using all four limbs - is probably the ancestral locomotor mode for primates but also the most widespread behaviour among the living species (Rose, 1973) (Fig. 1A). It can be slow and deliberate, like in lorises, or very fast and acrobatic as seen in many lemurs and New and Old World monkeys. It is never an exclusive locomotor mode: arboreal quadrupedal primates also move frequently by leaping and climbing. Terrestrial quadrupedalism is not as widespread as its arboreal 
counterpart, occurring only in larger cercopithecine monkeys such as patas monkeys and baboons (Fig. 1B). A specialised form of quadrupedalism is the terrestrial knuckle walk practised by gorillas and chimpanzees (Fig. 1C). Since these great apes have very long forelimbs, their trunk position is more oblique than that of other quadrupeds. Fore- and hindlimbs are kept straight and the knuckles of the hands carry the weight of the body's forequarter.

Quadrupeds generally use different gaits for progression. Gaits appear during steady locomotion and involve regularly repeated cycles of limb movement. Walking and running are symmetrical gaits in which the feet of a limb pair move alternately at equal intervals (Gambaryan, 1974; Hildebrand, 1966). The body moves forward along an almost straight line parallel to the substrate. Up and down motions of the body are largely reduced to save energy. To ensure smooth progression, the fore- and hindlimbs need to have the same functional length, which is the linear distance between the proximal pivot and the point of contact between the support and the hand or the foot. When their functional length is the same, the limbs can move with the same angular excursion and frequency and there is no discrepancy between step lengths (Schmidt, 2008).

Asymmetrical gaits are faster than symmetrical gaits because they always include aerial phases between the contact periods of the limbs (Fig. 1D and E). Primates gallop or bound as their fastest modes of quadrupedal locomotion. Bounding is more frequent in smaller primates. In bounding, the feet of each pair are set down simultaneously, whereas in a gallop the feet of each pair are slightly out of phase. The power required to propel the body is no longer produced by the limbs alone, but additional flexion and extension of the spinal column considerably increase stride length. Sagittal bending of the trunk and powerful hindlimb extension produce almost all the propulsive force, with the forelimbs functioning as braking struts (Demes et al., 1994). In contrast to symmetrical gaits, galloping and bounding involve extensive up and down movements of the body.

Primate quadrupedalism follows the general principles of quadrupedal locomotion in mammals in many respects, but there are some significant differences between primates and other mammals which originate in the use of small locomotor supports (Cartmill, 1972; Cartmill et al., 2002; Lemelin et al., 2003; Rollinson and Martin, 1981; Schmitt, 1999). Small supports require balance and compliance - the first to keep the body above the support and the second to cope with the instabilities and overall discontinuities of the arboreal habitat. For both purposes, primates rely on their grasping extremities which always guarantee a firm grip around a thin branch. Additionally, many primates use a specific footfall sequence in which a forelimb is placed after the contralateral hindlimb has been set down. This "diagonal sequence" is combined with "diagonal coupling" whereby the limbs of a diagonal limb pair are placed very close in time (Hildebrand, 1967). The advantage of this diagonal sequence-diagonal coupling pattern on arboreal substrates is twofold. The simultaneous contact of a diagonal limb pair is optimal for balance and the contact of a hindlimb prior to the next forelimb increases safety because the hindlimb is placed on a previously tested support. If the next forelimb then touches a breaking twig, body weight can be shifted onto the hindlimb (Cartmill et al., 2002). This strategy is even more effective in larger primates whose hindlimbs are longer in relation to their forelimbs and thus reach further forwards, allowing them to be placed closer to the ipsilateral forelimb. In this way, many primates carry a large portion of their body weight on their hindlimbs (Demes et al., 1994; Kimura et al., 1979; Raichlen et al., 2009).

Symmetrical and asymmetrical gaits produce conflicting demands on the morphology of an animal which regularly uses both types of gaits. Fore- and hindlimbs should ideally have equal lengths for walking but hindlimbs need to be longer than forelimbs for galloping and bounding. Longer hindlimbs enhance acceleration, which depends on the time and the distance available for limb extension. For this reason, arboreal quadruped primates generally have longer hindlimbs than forelimbs because they also move frequently by leaping (Jungers, 1985). Only the lorises display almost equal fore- and hindlimb lengths - probably because they never adopt asymmetrical gaits or move in leaps.

\subsection{Climbing}

The ability to climb is omnipresent in living primate species and fundamental to an arboreal lifestyle. It allows primates to ascend or descend in a highly structured and discontinuous environment. Climbing cannot be dismissed as walking on inclined substrates but differs substantially from walking in its irregularity. Climbing is not a form of steady locomotion in which primates can rely on regularly repeatable cycles of limb movement and a consistent pattern of interlimb coordination. The irregularity involved demands a higher amount of control and assistance from the main sensory organs (e.g. the eyes). It therefore seems reasonable to suggest that of all the locomotor modes of primates, climbing is most likely to have promoted the development of cognitive skills during primate evolution. Climbing requires hand-eye coordination and the conscious estimation of distances and substrate properties. Grasping extremities are an important prerequisite for climbing because they provide stable holds in any position. The tail, if present, is often used as an additional prehensile organ, not only in those primates that like howler monkeys or spider monkeys - have specialized prehensile tails. Limb excursions are large and highly threedimensional during climbing. It was this mode of movement which earned primates the name "Quadrumana" among past scientific authorities (Cuvier, 1817).

Its irregularity makes it difficult to cram all climbing activities into a standardized definitional framework. Hunt et al. (1996) distinguished twelve sub-types of vertical climbing 


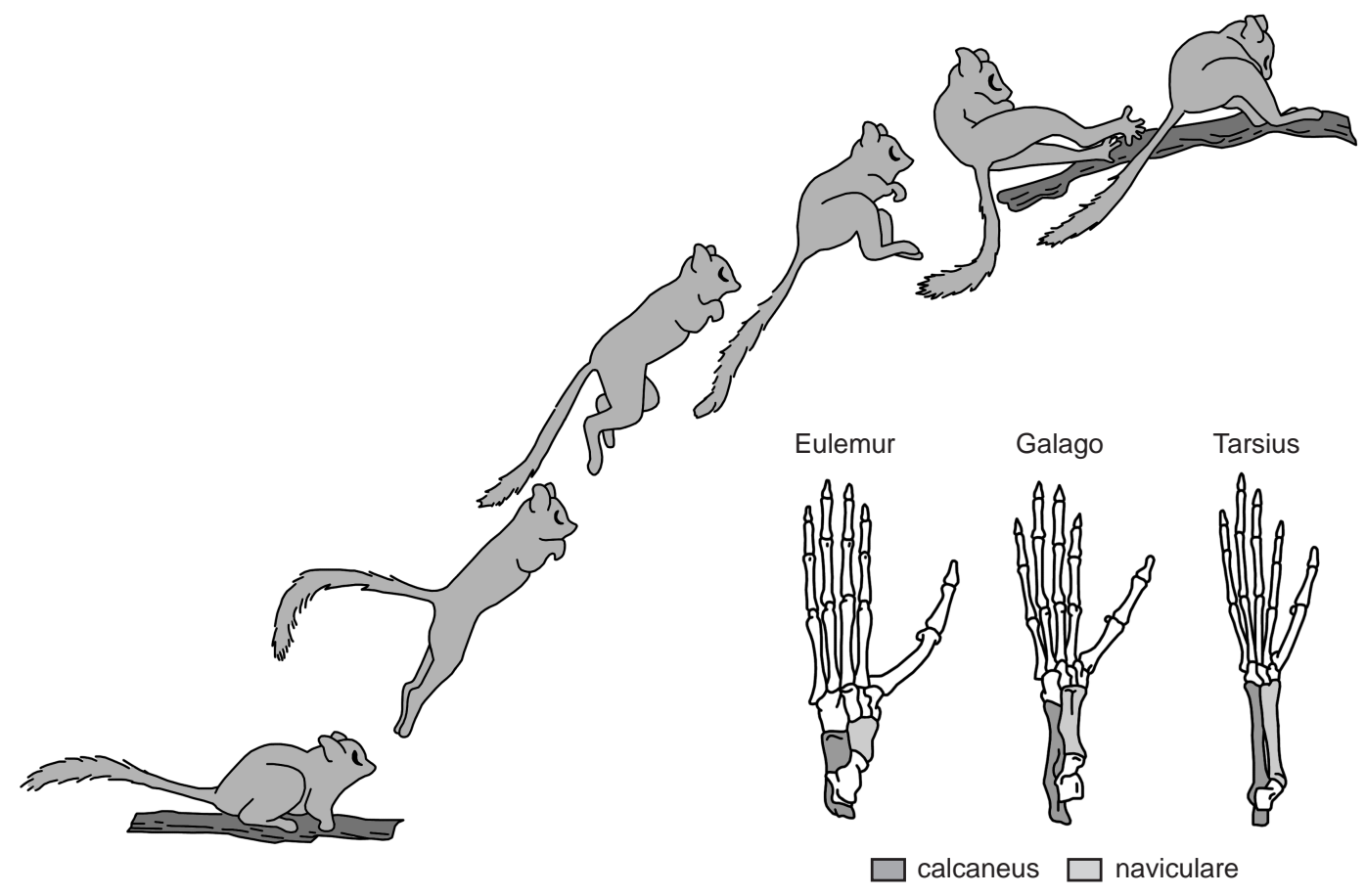

Figure 2. Leaping sequence of a bush baby (Galogo senegalensis) and leaping adaptations in the foot of Galago and Tarsius compared to the foot of Eulemur. Note the elongation of the tarsal bones (naviculare and calcaneus) in the leaping specialists (drawn after Grzimek (1988)).

on steeply inclined or vertical substrates according to trunk position, limb support and limb interaction. The authors reject the use of the term "climbing" for any horizontal movement. Although inclination is a parameter which should be possible to objectify from a physical perspective, each primate species is differently equipped to deal with inclination, so degree of steepness is actually a highly subjective measure. For some primates, vertical climbing is as easy as horizontal walking, but for others it is not (Hanna et al., 2008). If inclination were the only criterion, the distinction between walking and climbing would be arbitrary. Irregularity of limb use, slow and cautious movement and a higher degree of cortical control are probably much better factors to characterize climbing in primates.

\subsection{Leaping}

Primates usually leap to cover a discontinuity in their habitat or to rapidly change their location in escape situations. Leaping is the covering of distances in free flight. It may take place between inclined, vertical or horizontal substrates (Fig. 2). Like climbing, the ability to leap is therefore an important component of the locomotor repertoire of arboreal primates. Leaping is not usually a cyclic form of locomotion and is thereby distinguished from hopping. The latter form of motion is well known from the Malagasy sifakas, which perform impressive displays of bipedal hopping on the ground. A leap is normally a singular event. It involves the acceler- ation of the body at take-off to overcome gravity and controlled deceleration during landing to reduce impact forces.

Simple ballistic considerations mean a leap can either be very high or very long, depending on the take-off angle between the body and the ground. The distance a primate can leap depends on its kinetic energy $\left(1 / 2 m v^{2}\right)$ at the end of the take-off phase when it leaves the ground. To gain this energy the body is accelerated via a rapid extension of the back and the hindlimbs. Because of its intimate relationship to gravity, leaping is more influenced than climbing by the body size of a primate. Size-related morphological adaptations to improve leaping and, particularly, acceleration are therefore common in arboreal primates. Such adaptations include, for example, limb elongation and higher muscle masses (Demes and Günther, 1989; Grand, 1977; Jungers, 1985). During free flight, there may be a rotation of the trunk which swings the hindlimbs into a position in front of the body to break the impact of landing. The momentum necessary to rotate the body during flight is produced by the tail. Primates which regularly leap always have long tails. In turn, the shortening or complete reduction of the tail indicates the absence or minor importance of leaping in the locomotor repertoire of a given species, as is the case with the lorises and the lesser and great apes.

The small-sized galagos and tarsiers display a highly specialised form of leaping which was originally elevated to its own locomotor category "vertical clinging and leaping" (Napier and Walker, 1967), in which the larger-sized 
Malagasy indris and sportive lemurs also featured. Vertical clingers and leapers as a group are united by unique postural and locomotory habits. They usually cling on to and leap from and to vertical supports. Despite the apparent uniformity of the behaviour, there is considerable morphological diversity within vertical clingers and leapers which mainly results from differences in body size and associated differences in leaping mechanics (Demes et al., 1996; Stern and Oxnard, 1973). Tarsiers and galagos propel themselves via a rapid extension of the ankle joint and have elongated tarsal bones which function as lever arms for the ankle extensor muscles (Jouffroy and Gasc, 1974) (Fig. 2). The large indris, on the other hand, accelerate by means of a rapid extension of the hip joint and have elongated thighs (Demes et al., 1996; Jouffroy and Lessertisseur, 1979). The indri's foot is also long, but it is built more for grasping than for propulsion (Gebo and Dagosto, 1988).

\subsection{Suspension}

Suspension is both a locomotory and a postural behaviour depending on whether or not a significant distance is covered. The limbs are loaded in tension, which is why many primates keep them straight as they hang. Limb extension reduces the muscular effort needed to bend the limb joints against gravity. Suspensory locomotion can basically be subdivided into two modes, one in which the body is kept in a pronograde position more or less parallel to the support, and the other involving an orthograde or erect body position (Hunt et al., 1996). Pronograde suspension is an inverted quadrupedal walk or run with extended limbs, often accompanied by the use of a prehensile tail.

Orthograde suspension, supported either by the forelimbs or the hindlimbs, is a widespread postural behaviour during foraging and feeding in New and Old World primates, but suspensory locomotion using arm swinging is displayed by only a few primate species. This mode of locomotion is termed "brachiation" (Keith, 1923). Among New World primates, the spider monkeys frequently swing from branch to branch by the arms, mostly aided by the prehensile tail. Some African colobines and Asian leaf monkeys are able to perform arm swinging but seldom practise this mode of locomotion. Brachiation constitutes an important part of the locomotor repertoire of Hominoidea and is responsible for a suite of derived features in their motion system (Erikson, 1963; Gebo, 1996; Keith, 1923). The most sophisticated form of brachiation can be observed in gibbons and may include a phase of free flight between two handholds. Using this ricochetal type of brachiation gibbons are able to throw themselves from one tree to the next over gaps of $10 \mathrm{~m}$ and more and can move at speeds of up to $50 \mathrm{~km}$ per hour, making them the fastest brachiators in the primate world.

Suspensory primates have characteristic hook-like hands with a thumb that may be reduced in size. In terms of body proportions, suspensory primates have long forelimbs. The shoulder region in particular displays adaptations that enhance the ability to reach supports in many directions. The scapula is positioned on the dorsal side of the trunk rather than on the lateral side as it is in quadruped primates. The shoulder joint of suspensory primates is therefore more mobile than that of all other primates. The wrist joint is also extremely mobile, permitting a tremendous range of arm rotation around the hand hold. Another important prerequisite for suspensory locomotion besides mobility is sufficient muscular strength (Preuschoft and Demes, 1984).

\subsection{Bipedalism}

Bipedalism is more widespread among primates than might be expected. Many primates occasionally walk on their hindlimbs when carrying food objects or infants. Facultative bipedalism of this kind has been observed in certain New World monkeys such as capuchins and spider monkeys and in many Old World monkeys (Napier and Napier, 1967). Gibbons walk bipedally in their arboreal environment on large horizontal boughs, often with their long arms raised above their heads to assist with balance or provide additional hold. Chimpanzees and Bonobos may walk bipedally on the ground. The bipedalism of these African apes is characterized by a relatively rigid body, bent hips and bent knees.

Human bipedalism is different from these modes of facultative bipedalism. Humans walk habitually on their hindlimbs and show particular adaptations to this mode of locomotion. Functional adaptations include that only humans are able to move upright with straight knees and straight hips over long distances. Human walking is further characterized by a systematic use of trunk rotation around the waist resulting in a diagonal coupling of the swinging arm and leg (Witte et al., 2003). We know of a suite of morphological adaptations related to this mode of bipedalism, the most striking of which being as follows: the vertebral column of humans shows a characteristic dual curvature with a dorsal convexity in the thoracic region and a ventral convexity in the lumbar region. The pelvis is short but broad. The femur is aligned obliquely so that the knees, legs and feet are placed beneath the body. The foot bones are fundamentally transformed and rearranged. The human foot has two bony arches acting as spring-like shock absorbers. The big toe is aligned with the other toes. Humans are the only primates who lack an opposable hallux.

\section{Determinants of diversity in locomotor behaviour}

The diversity of locomotor behaviours among living primates is the product of around 80 million years of primate evolution (Arnason et al., 1998; Tavaré et al., 2002). We now have reliable evidence to support the hypothesis that the last common ancestor of all living primates was a small nocturnal animal weighing not more than $500 \mathrm{~g}$. This animal likely inhabited tropical forest where it travelled quadrupedally and 
foraged for insects, flowers, and fruits in a highly structured habitat: the terminal branches and twigs of the canopy (Cartmill, 1972, 1974; Rose, 1973; Sussman, 1991; Ravosa and Dagosto, 2007). Here, the earliest primates found a large amount of energetically rich food for which, if they were not nocturnal, they would compete only with birds. The key features that primates developed to forage successfully in this habitat were stereoscopic vision and grasping extremities. The powerful grasping foot not only enables primates to move cautiously on small and unstable supports, it also provides a firm grip when the hands release the support to catch insects or pick a flower. This foraging behaviour can still be observed in several living forms such as mouse lemurs or galagos, which are often regarded as "models" for the last common ancestors of primates (Charles-Dominique and Martin, 1970; Gebo, 2004). This behaviour also illustrates that grasping extremities are not a pure locomotor adaptation. The fine-grip capability of the hand, the development of finger pads covered with volar skin and the transformation of claws into nails are all likely to be better explained in relation to catching, picking and holding food. In contrast, the powerful opposability of the nail-bearing great toe of the primate foot is needed to balance body weight during both posture and locomotion.

Both the diversity of primate locomotor behaviour and behavioural variation within a species or a population of primates results from differences in body size, habitat, and the immediate behavioural context behind locomotor activities. Generally speaking, the diversity of locomotor behaviour among primates is the product of ultimate factors acting during evolution and proximate factors acting during the life history of an individual. Body size is both an ultimate and a proximate factor because it changes during the evolutionary history of the order primates but also during the ontogeny of each primate individual. Habitat structure largely determines behavioural differences among populations of the same species, but is also an evolutionary determinant - mainly because of the intimate relationship between body size and habitat. The behavioural context of a particular activity may be a predominant proximate factor, but the great plasticity of possible interactions between an individual and its environment is also the product of evolution.

\subsection{Locomotor behaviour and body size}

An increase in body size was a major trend in the evolution of both strepsirhine and haplorhine primates. Since the last common ancestor of both groups was likely a small animal, the size increase in the two groups occurred as parallelism (Martin, 1990) and size-related similarities between members of the groups can be regarded as parallel adaptations to the same problems. Interestingly, dwarfism - the evolutionary decrease in size - is rare among primates. The best known examples are the marmosets and tamarins of the New World (Ford, 1980).
Body size has a fundamental influence on all physical and physiological properties of an organism (Gould, 1966; Peters, 1986; Schmidt-Nielsen, 1975). The way that structures and functions change with size is described by the term "scaling". Changes in body size have consequences for virtually all biological structures and functions, including locomotion and the musculoskeletal system. There is a simple geometric relationships between linear dimension, area, and volume that results in a decreasing ratio between surface area and volume if the body size of an animal increases without any changes in shape. This has significant consequences for locomotion and posture because body mass is a volume-based variable that produces weight force under the influence of gravity. This weight force must be sustained by the bones and muscles, but muscle force and bone strength depend on the cross-sectional area of these structures. If all dimensions were to change isometrically to body size, then, heavier animals would have relatively weaker muscles and bones. The departure from isometry is called allometry. Allometric changes in body structures are one way of resolving the problems which accompany changing body size. Generally however, the physical and physiological consequences of size changes are managed both through morphological adaptations and by adjusting function, e.g. the limb bones of larger primates are more robust but the limbs are also moved in a straighter fashion to reduce bone stress and muscle load (Biewener, 1983; Demes and Günther, 1989). As a consequence, certain locomotor modes may be expected to appear predominantly in small-sized primates, whereas others would seem more likely to be preferred by largersized species. In practice, size differences among primates are mainly reflected in the frequency a particular locomotor mode is used. There is no locomotor behaviour which is performed exclusively by large or exclusively by small primates - unless it has a phylogenetic background, as is the case with brachiation or knuckle walking. However, a small body size seems to be extremely advantageous in the exploitation of the arboreal environment, especially the small branch habitat. Most supports are large enough to provide stability and balance. Branches bend only slightly under the weight of the animal and only a small amount of force is needed to leap over large distances. A small body size also has drawbacks in locomotion, though. A small primate can hardly anticipate its next walking or running step, and nor can it anticipate where it will land after a jump. Its whole environment is so highly structured and discontinuous that the major sensory organs (e.g. the eyes), thought to guide the locomotion of large primates; probably fail to provide useful control, especially if motion is fast. The motion of small primates is therefore like that of any other small mammal equipped with various strategies for self-stability which help it to return to equilibrium after encountering an obstacle or landing on a breaking twig (Fischer and Blickhan, 2006; Schmidt, 2008). In the worst case scenario of falling from a tree, a small primate would again benefit from its size because the amount 
of energy to be absorbed by the body at impact would be much lower than for a larger primate. Plummeting from a tall tree normally causes no serious injury to a small primate. As body size increases, however, balance, stability, compliance, and the risk of falling become increasingly important for arboreal primates. Larger primates therefore carry out above-branch activities primarily on larger supports, but below-branch activities on smaller branches to avoid potential problems with balancing (Grand, 1984). More cautious forms of progression such as climbing generally become predominant with increasing size. Additionally, there is a trend towards increased use of suspended postures and locomotor modes and a decreasing frequency of leaping the larger arboreal primates become. Striking exceptions are provided by some of the relatively large leaf-eating monkeys. Langurs are known for crossing gaps in the canopy in huge and risky leaps which are also part of their display behaviour (Ripley, 1967). Members of the New World Atelidae display various specializations for below-branch activities, for which they use their prehensile tail together with their four limbs in all possible combinations. In most other mammalian groups there is a strong tendency towards terrestrialism as body size increases. In primates, however, this "option" is rarely taken. Among strepsirhine primates, only the ringtailed lemur spends significant time on the ground, but for reasons other than those related to size. True terrestrial primates exist only among Old World Cercopithecinae. The New World is home to no ground-living primates at all. Even the largest living primates, the great apes, engage in many arboreal activities.

\subsection{Locomotor behaviour and habitat}

The adaptive value of a particular locomotor behaviour, i.e. its biological role, can only be understood by considering the habitat in which the locomotion is performed (Bock and von Wahlert, 1965). Field studies are therefore the most informative and reliable source of insights into the adaptive diversity of locomotor modes and their interspecific and interindividual variability. Numerous field studies on primate locomotor and postural behaviour have accumulated over the years, covering a broad range of primate genera (e.g. Doran and Hunt, 1994; Doyle and Martin, 1979; Fleagle et al., 1981; Fleagle and Mittermeier, 1980; Garber, 1991; Gebo and Chapman, 1995; Martin, 1972; McGraw, 1996; further references in Fleagle, 1999; Nowak, 1999; and Rowe, 1996). These and many other studies reveal not only that most primates have multiple behaviours in their repertoires, but also that the frequency of a particular behaviour is significantly affected by the habitat in which a primate species occurs.

Living primates can be found in a variety of habitats. While a few species live in dry regions with sparse vegetation, the majority of primates inhabit tropical forest. Even here, the different types of forest represent quite different locomotor habitats. Primary rain forests are characterized by a distinct canopy structure up to $40 \mathrm{~m}$ high in which habitats for locomotion differ greatly from those on ground level. Near the ground there are more vertical supports such as trunks and lianas, while in the canopy the supports are continuous and more horizontal. Primates inhabiting primary forest display considerable interspecific variation in the level at which they forage, rest, and travel. Secondary forests have denser and more continuous vegetation throughout the strata. Strong contrast can also be found in bushlands and savannah, where a few short trees and bushes are spread over a wide area covered with grasses. Forest types, bushland and savannah might be examples of habitat diversity from a human perspective, but this is the perspective of an outsider. A primate living and moving within these habitats would probably perceive other structural parameters to be more relevant. Support size, inclination, compliance, density, and spatial patterning are more likely to be the crucial architectural variables of an arboreal locomotor habitat, and all play important roles in the choice of locomotor modes. Furthermore, none of these variables is an absolute parameter, but must always be seen in relation to the body size of the primate species under consideration.

Even for a single species habitat is far from being a constant variable, as many species have wide distributions throughout structurally dissimilar habitats. Field researchers, who have addressed the question of how the locomotor activities of a single species change with changing habitat architecture, have found that some species display little variation while others show significant alterations in their locomotor activities. At least for some species, locomotion is more conservative than habitat utilization and support use will change before accompanying locomotor behaviours do (McGraw, 1996).

\subsection{Locomotor behaviour and behavioural context}

Another important source of variation in locomotor behaviours beside body size and habitat is the behavioural context in which locomotor activities appear to be used. The different contexts of locomotor activities are the most influential factors in individual behavioural plasticity. Travel, forage, and escape each demand different skills and different strategies because they all have different aims. The aim of travel is to cover a specific distance within the home range of an individual or a group in a certain amount of time, whereas foraging behaviour is immediately directed at collecting and consuming food. Escape from predators or aggressors requires high speeds to be reached quickly. Locomotor behaviours must thus differ in terms of support use, limb coordination and speed according to these different aims.

Primates usually spend most of their daily activity periods not in locomotion but resting, feeding, self-grooming and engaging in social activities. The amount of time taken up by travel and foraging varies enormously, not just among primate species but also among populations of the same species 
(e.g. Dagosto, 1995; Fleagle et al., 1981; Gebo and Chapman, 1995; Rose, 1974). It largely depends on dietary specializations, the location of preferred food sources and the size of the home range; all factors which may change seasonally.

Locomotion during foraging in the arboreal environment is the slowest and most cautious activity which primates engage in. Since it normally takes place in the most discontinuous and instable regions of the terminal branches and twigs, the predominant behaviour is climbing. Most primates extend their foraging radius by hanging below supports with their hands, feet or a combination of both. Hindlimb suspension is a very common feeding posture in primates. Large primates in particular switch from climbing to suspensory activities if the branches are too small to carry their weight (Grand, 1984). The grasping extremities always provide secure holds and the tail, if present, is often used as an additional prehensile organ. Limb excursions are large and highly threedimensional. The distinction between locomotory and postural behaviour is effectively arbitrary during foraging, as it is in many other behavioural activities such as display, fighting and playing.

For the majority of primates, quadrupedal walking and running are, along with leaping, the preferred modes of travel. Generally, arboreal primates spend a smaller part of their activity budget in travelling, particularly during seasons when food resources are abundant. But, during seasonal food shortages, both travel and foraging usually cover a greater part of the activity budget combined with seasonal shifts in the frequency of certain locomotor modes (Boinski, 1989; Crompton, 1984; Dagosto, 1995; Gebo and Chapman, 1995). Terrestrial primates such as baboons and patas monkeys usually travel for longer distances and usually forage while travelling (Rose, 1974). Support use is often less variable during travelling than during foraging. Many arboreal primates even have established travel paths in their home range. These paths consist of large, continuous and mostly horizontal branches which provide safety even at high speeds.

Escape is among the most critical activities because it places maximum stress on the motion system. The ability to escape from predators particularly is decisive in the survival of each individual and constitutes an important selective component. The unique ability of primates to move safely on the most discontinuous and uncertain locomotor substrates in the periphery of the tree crown puts them in with a good chance of avoiding predators. In these regions of the forest, primates are able to outpace most of their "terrestrial" predators such as viverrids and felids. Leaping is the fastest mode of progression by far and is therefore the prevailing means of motion during escape. This makes it unsurprising that morphological adaptations to leaping are found in the majority of arboreal primates even if quadrupedal locomotion is their most frequent locomotor activity. With increasing body size however, the need to escape from predators may be reduced.
Large terrestrial primates such as baboons or African apes are successful fighters and thus do not always need to escape when confronted with a predator.

\section{Locomotor preferences within primate families}

The following information and observations on the locomotor behaviours of primates are compiled from various primary and secondary sources: Ashton and Oxnard (1964), Boinski (1989), Doyle and Martin (1979), Fleagle (1999), Fleagle et al. (1981), Fleagle and Mittermeier (1980), Fontaine (1990), Garber (1991), Gebo (1987), Gebo and Chapman (1995), Grizimek (1988), Hershkovitz (1977), Martin (1990), Nowak (1999), and Walker (1979). The boxes contain specific information about locomotor preferences of some of the mostly utilized laboratory primates. Comprehensive information about many other primate species is also available at the web side "Primate Info Net" (National Primate Research Center, University of Wisconsin, Madison).

\subsection{Strepsirhini}

\subsubsection{Lemuriformes}

Daubentoniidae: The locomotion of the aye-aye (Daubentonia madagascariensis) is much like that of a lemur, with a preference for quadrupedalism in the trees and on the ground. While walking, the extraordinarily long fingers are held in a curled position for protection. Pronograde suspension under large horizontal branches is also common. Leaps over quite large distances are often made. The locomotor repertoire of the aye-aye is further characterized by a high frequency of head-first descent, mainly during foraging when the animal listens carefully for the sound of insect larvae boring their way into the bark of the tree.

Cheirogaleidae: Mouse lemurs (Microcebus) and dwarf lemurs (Allocebus, Cheirogaleus, Mirza and Phaner) are relatively small arboreal primates whose movements generally appear to the human eye as scurrying. Quadrupedal walking, running and bounding are their most frequent modes of progression on horizontal branches. Their limbs are relatively short and crouched so that the body is held close to the support (Box 1). Climbing, leaping and suspensory movements are also very common. Unusually for primates, these species climb down large trunks head first, like squirrels.

Lepilemuridae (Megaladapidae): Sportive or weasel lemurs (Lepilemur) are also quite small and weigh less than 1000 grams. Like cheirogaleids they are arboreal forest dwellers and strictly nocturnal. They normally move in rapid leaps from one vertical support to another using a powerful extension of the long hindlimbs. On the ground they usually progress in bipedal hops in a kangaroo-like manner. Quadrupedalism may be used for slow progression.

Indridae: Active arboreal locomotion in woolly lemurs (Avahi), sifakas (Propithecus) and indris (Indri) consists of 


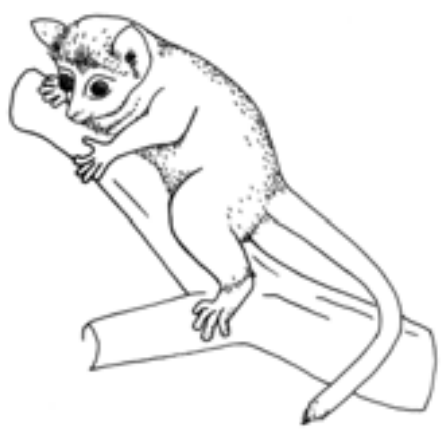

Box 1: Locomotor characteristics of gray mouse lemurs (Microcebus murinus, Cheirogaleidae).

Physical characteristics:

- Head and body length: 125-150 mm

- Tail length: $135 \mathrm{~mm}$

- Body mass: 80-100 g

- relative short limbs, mean Intermembral Index $(\mathrm{IM})=73$

Natural habitat:

- secondary forest, dry deciduous gallery forest, dense vegetation

- home range: 0.07-2 ha

- night range: unknown

Locomotor preferences:

- agile arboreal quadrupedalism, walking and running, leaping

Substrate preferences:

- branches and twigs of very small diameter $(<10 \mathrm{~mm})$, horizontal to slightly inclined

- supports, vertical substrates used for leaping

References and further readings: Doyle and Martin (1979), Martin (1972, 1973), Nowak (1999), Rowe (1996), Walker (1979)

leaps from one vertical trunk to another in the understory of the forest. The hindlimbs of indrids are about one-third longer than the forelimbs and the tail is also very long (except in the case of the indri, which has no tail). Quadrupedalism and suspension are not common, while the frequency of climbing is high. Sifakas often use bimanual movements, including brachiation, although for short periods of time only. Progression along large horizontal branches and on the ground takes the form of bipedal hopping.

Lemuridae: The true lemurs (Eulemur) and the ruffed lemurs (Varecia) are highly arboreal primates. Active quadrupedalism, leaping and climbing constitute the main body of their locomotor repertoire. They all prefer to move on the upper surface of horizontal or slightly inclined supports. Hindlimbs are generally longer than forelimbs. The tail is actively used in balancing above narrow supports and in controlling body rotation during leaping. Suspension is

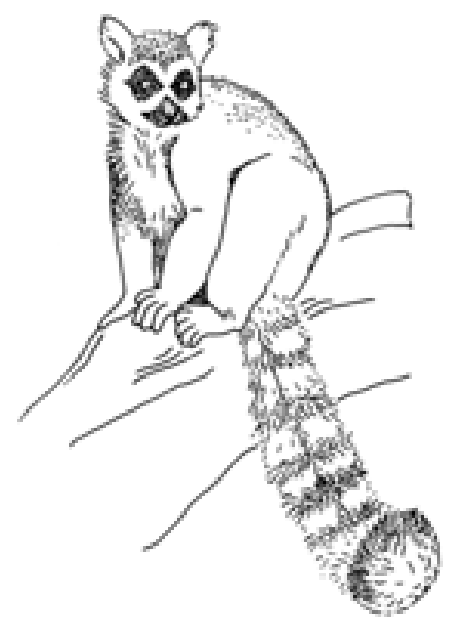

Box 2: Locomotor characteristics of ring-tailed lemurs (Lemur catta, Lemuridae).

Physical characteristics:

- Head and body length: 385-455 mm

- Tail length: 560-624 mm

- Body mass: 2200-2700 kg

- relative long hindlimbs, mean $\mathrm{IM}=70$

Natural habitat:

- gallery forest along rivers, spiny bush forests

- home range: 6-35 ha

- day range: $\sim 1400 \mathrm{~m}$

Locomotor preferences:

- quadrupedal walking, running, climbing, and leaping

- spending more time on the ground than other lemurids

Substrate preferences:

- large oblique branches in the lower forest levels for foraging, feeding, and resting

- ground for travel

References and further readings: Nowak (1999), Rowe (1996), Walker (1979), Ward and Sussman (1979)

common during foraging using all possible variations of the four limbs. The ring-tailed lemur (Lemur catta) stands apart from the other lemurs somewhat in its distinct preference for travelling on the ground, where it mostly moves quadrupedally (Box 2). Bipedal hopping is also very common on the ground. When in trees, ring-tailed lemurs engage in leaping and climbing like other lemurs. Bamboo lemurs (Hapalemur) show a greater preference for clinging onto and leaping between vertical supports and are far less quadrupedal than the other lemurs. They climb downwards tail first as do all lemurs. Bipedal hopping is often used both on branches and the ground. 


\subsubsection{Loriformes}

Galagonidae: Galagos are primarily leapers but the locomotor preferences of the various species cover a broad spectrum, from quadrupedalism to specialized vertical clinging and leaping. The greater galagos of the genus Otolemur move mainly by quadrupedal walking and running and express a preference for horizontal supports. The lesser bushbabies (Galago, Galagoides) are all smaller than Otolemur, have relatively longer hindlimbs and are spectacular leapers. Their bushy tails are usually longer than their body. The lesser galagos travel almost exclusively by leaping. The needle-clawed galago (Euoticus elegantulus) moves both quadrupedally and by leaping.

Loridae: The locomotion of the Loridae is very different from that of their sister taxon. Lorises (Loris, Nycticebus) and pottos (Arctocebus, Perodicticus) usually progress using slow, deliberate and highly controlled movements. They travel along the underside of branches as readily as along the top. Loridae are acrobatic climbers with very long and mobile limbs. The elongated spine is used extensively in sinuous side-to-side movements. Slender loris and pygmy loris can move quickly at times but none of the Loridae can leap or jump. Accordingly, the forelimbs and hindlimbs are nearly equal in length and the tail is reduced. The first digit of each limb is widely opposable to the other digits and the grip is very powerful.

\subsection{Haplorhini}

\subsubsection{Tarsiiformes}

Tarsiidae: The small tarsiers (Tarsius) are highly specialised vertical clingers and leapers. Their forelimbs are short, but their hindlimbs are greatly elongated. The name "tarsier" refers to the elongated tarsal region of the foot. Tarsiers are notable acrobats in trees, making quick leaps of several metres with no apparent effort. Maximum leaping distances of 5-6 $\mathrm{m}$ are reported. On the ground, progression is by bipedal hopping.

\subsubsection{Platyrrhini}

Aotidae: The owl monkeys (Aotus) are predominantly quadrupedal but are also adept leapers. They are found in a variety of forest habitats. Limbs and tail are relatively long, indicating the generalized nature of their locomotor behaviour.

Cebidae: The capuchin monkeys (Cebus) and squirrel monkeys (Saimiri) are essentially quadrupedal and very active primates. They forage among the smaller branches in the upper (Cebus) or lower (Saimiri) strata of the primary South American tropical forest (Box 3). Capuchins have long, moderately prehensile tails which they use for additional hold during foraging and feeding. During travel, cebids make frequent leaps to cross gaps between the big branches of the

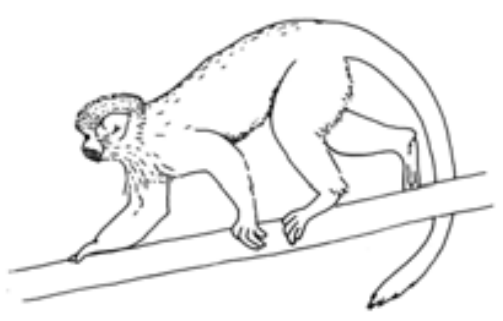

Box 3: Locomotor characteristics of common squirrel monkeys (Saimiri sciureus, Cebidae).

Physical characteristics:

- Head and body length: 260-360 mm

- Tail length: 350-425 mm

- Body mass: 750-1100 g

- slender body, relative long limbs, mean IM = 79

Natural habitat:

- primary and secondary forest, riverine forest, lower strata and understory, occasional on the ground

- home range: 65-130 ha

- day range: $\sim 1500 \mathrm{~m}$

Locomotor preferences:

- active arboreal quadrupedalism, walking and running, leaping,

Substrate preferences:

- small branches and twigs (diameter $<20 \mathrm{~mm}$ ) of various inclination for foraging

- more horizontal branches for travel

References and further readings: Arms et al. (2002), Boinski (1989), Fleagle and Mittermeier (1980), Fleagle et al. (1981), Nowak (1999), Rowe (1996), Vilensky and Patrick (1985)

middle layers. Sometimes they descend to the ground. Capuchins are the most dexterous monkeys in the New World. They have a true opposable thumb and display a variety of precision grips.

Callitrichidae: Marmosets (Callithrix, Mico, Cebuella) and tamarins (Leontopithecus, Saguinus) are the smallest living New World monkeys. They are characterized by sharp curved claw-like nails on all digits except the hallux, which bears a flattened nail (Box 4). This adaptation enables them to cling to the sides of large tree trunks where they feed on exudates or search for prey. Generally, callitrichids climb and run rapidly on all fours with jerky movements. Mediumsized substrates are preferred over very small branches and twigs. Goeldi's monkeys (Callimico goeldii) are somewhat larger in size than the marmosets, their closest relatives, but they move in a similar fashion mainly by leaping from trunk to trunk a few metres off the ground. 


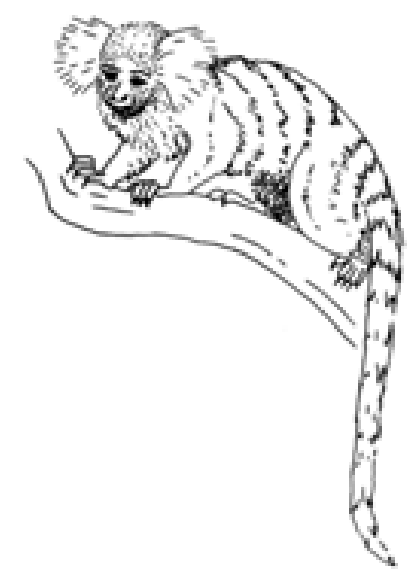

Box 4: Locomotor characteristics of common marmosets (Callithrix jacchus, Callitrichidae).

Physical characteristics:

- Head and body length: 160-210 mm

- Tail length: 250-300 mm

- Body mass: 200-325 g

- relative short limbs, mean IM $=75$, claws instead of nails on all digits except the great toe

Natural habitat:

- dry and secondary forest, lower levels

- home range: $0.5-6.5$ ha

- day range: 500-1000 m

Locomotor preferences:

- agile arboreal quadrupedalism, walking and running, clinging to and leaping between large vertical supports

Substrate preferences:

- vines and small branches (diameter 10-15 mm) of various inclination, exudate feeding and foraging for insects on large trunks

References and further readings: Hershkovitz (1977),

Nowak (1999), Rowe (1996), Rylands (1993)

Pitheciidae: The medium-sized sakis (Pithecia), bearded sakis (Chiropotes) and uakaries (Cacajao) live in a wide variety of forest habitats. All three genera travel quadrupedally in their customary forest layer, but leaping also plays an important role in their locomotor repertoire. Sakis are among the most saltatory of the New World monkeys and frequently move in spectacular leaps. Like in many small- and mediumsized primates, hindlimb suspension is a common feeding posture in sakis and uakaries.

Atelidae: The largest of the New World monkeys have developed prehensile tails with volar skin similar to the palmar surface of the hands which serve as a fifth limb in arboreal locomotion. Spider monkeys (Ateles), woolly spider mon- keys (Brachyteles) and woolly monkeys (Lagothrix) commonly use below-branch suspension during travel and foraging. Spider monkeys may swing from branch to branch by the arms and show particular adaptations to this mode of locomotion which, for example, facilitate the mobility of the shoulder region. In contrast, howler monkeys (Alouatta) are more quadrupedal and climb frequently. Leaping is a rare mode of progression in howler monkeys and woolly monkeys, but more frequent in spider monkeys.

\subsubsection{Catarrhini}

Cercopithecidae: Members of the subfamily Cercopithecinae descend from a primarily terrestrially adapted precursor, but many living species have returned to an arboreal lifestyle (Box 5). Nonetheless, quadrupedal walking and running is the predominant locomotor mode in this group and overall limb mobility is reduced in comparison to primarily arboreal primates. The forelimbs and hindlimbs of cercopithecines are long in relation to the trunk and almost equal in length to each other. They are generally kept straight during quadrupedalism. Despite the huge ecological differences between the cercopithecine monkeys, their locomotor modes and related morphological characters are fairly uniform and generalized. Baboons (Papio, Theropithecus), mandrills (Mandrillus) and patas monkeys (Erythrocebus) are the most terrestrial monkeys of any family (Box 6). Many species of mangabeys (Cercocebus, Lophocebus) and many guenons (Allenopithecus, Cercopithecus, and Miopithecus) are strictly arboreal. They have retained a long tail and can leap with great precision and strength. The locomotion of macaques (Macaca) is almost totally quadrupedal walking and running, with very little leaping and no suspensory behaviour (Box 7).

Members of the subfamily Colobinae have even longer limbs than cercopithecine monkeys. Limb mobility is also higher in this group, facilitating climbing - the preferred locomotor mode besides quadrupedal walking in these mostly arboreal primates. The African guerezas (Colobus, Procolobus) and the Asian langurs, leaf monkeys and proboscis monkeys (Semnopithecus, Presbytis, Pygathrix, Trachypithecus and Nasalis) all are good leapers, some making extraordinary and spectacular suicide leaps as part of their display behaviour. Suspensory movements including brachiation are occasionally used in some species. Proboscis monkeys are good swimmers.

Hylobatidae: Siamangs (Symphalangus), hoolocks (Hoolock) and gibbons (Hylobates, Nomascus) live and move in all levels of the dense tropical forest of Southeast Asia. They are certainly the most specialised brachiators and show a suite of distinctive adaptations to this mode of arm swinging. The length of their arms is enormous relative to their small bodies and their wrists are composed of a true ball-and-socket joint permitting 180 degrees of body rotation beneath the hand. The lesser gibbons (Hylobates) 


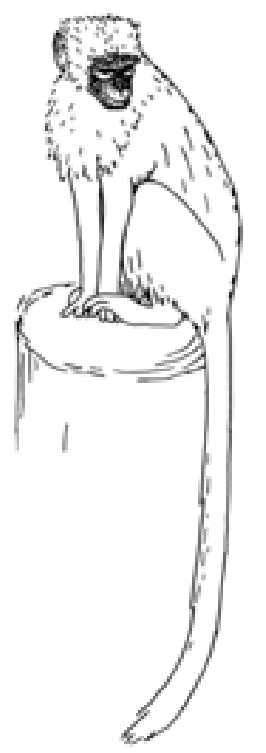

Box 5: Locomotor characteristics of vervet monkeys (Chlorocebus aethiops, Cercopithecidae).

Physical characteristics:

- Head and body length: 300-600 mm

- Tail length: 420-720 mm

- Body mass: 3500-8000 g

- sexual dimorphic in body size

- slender body, long and almost straight limbs, mean IM = 83

Natural habitat:

- habitat generalist: savannah, woodland to gallery and rainforest edge, rarely found in dense forests

- home range: 18-96 ha (seasonal variation)

- day range: 950-2000 m

Locomotor preferences:

- quadrupedal walking and running

Substrate preferences:

- feeding and traveling on the ground, resting in trees

References and further readings: Gebo and Sargis (1994), Nowak (1999), Rose (1979), Rowe (1996), Vilensky et al. (1988)

often practise the fast ricochetal brachiation which includes a flight phase between two successive handholds. Gibbons commonly climb vertical trunks and can walk bipedally along larger boughs.

Hominidae: Climbing, quadrupedal walking and armswinging are the predominant locomotor modes of our closest relatives, the Asian and African great apes. They all have very long arms and highly mobile limbs. The orang-utan (Pongo) spends most of its time in trees, where it climbs and moves cautiously or swings from branch to branch using al-

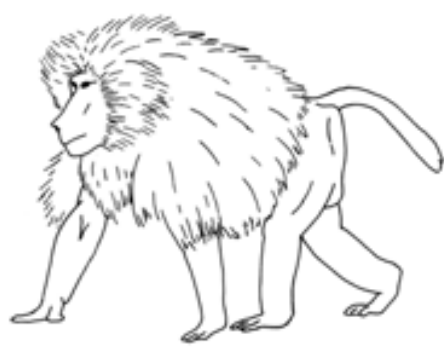

Box 6: Locomotor characteristics of Hamadryas baboons (Papio hamadryas, Cercopithecidae).

Physical characteristics:

- Head and body length: 610-762 mm

- Tail length: 382-610 mm

- Body mass: 9-21 kg

- distinct sexually dimorphic in body size

- long and straight limbs, mean IM = 99

- digitigrade hand postures may occur

Natural habitat:

- open woodland, savannahs, rocky hill country

- home range: 2800 ha

- day range: $6.5-19 \mathrm{~km}$

Locomotor preferences:

- terrestrial quadrupedalism, climbing in trees

Substrate preferences:

- travel and foraging on the ground, trees may be used for sleeping

References and further readings: Jolly (1967), Nowak (1999), Rowe (1996), Swedell (2002)

ternate arms. Immature individuals are more active and may move faster then the larger and heavier adults. Chimpanzees (Pan) are less arboreal than the orang-utans, but more so than the gorillas (Gorilla). On the ground, chimpanzees and gorillas progress using a particular form of quadrupedalism named knuckle-walking. In the trees, the movements of adult gorillas are slower and clumsier than those of chimpanzees. Due to their high overall body weights, great apes seldom leap.

\section{Practical implications for cage design and the management of primates in capticity}

Primates are very active animals. Their skeleto-muscular apparatus combines high mobility and high strength to a powerful high-performance motion system. Such a system is seriously underchallenged under captive conditions and may be impaired by a chronic imbalance between energy (i.e. caloric) intake and work output. The consequence can 


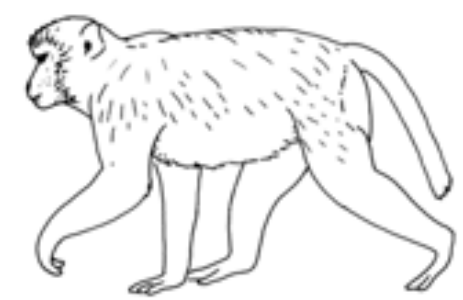

Box 7: Locomotor characteristics of rhesus macaques (Macaca mulatta, Cercopithecidae).

Physical characteristics:

- Head and body length: 460-532 mm

- Tail length: 208-228 mm

- Body mass: 5300-7700 g

- sexual dimorphic in body size

- stout body, strong and almost straight limbs, mean IM = 93

Natural habitat:

- habitat generalist: open grassland and woodland, frequently in urban habitats

- home range: up to 400 ha

- day range: 830-1900 m

Locomotor preferences:

- quadrupedal walking and running

Substrate preferences:

- largely depending on habitat, terrestrial and/or arboreal

- if arboreal, large to medium-sized branches are preferred

References and further readings: Dunbar (1989), Nowak (1999), Rowe (1996), Vilensky (1983), Wells and Turnquist (2001)

be overweight with its inherent risk for diabetes, cardiovascular diseases, muscle atrophy, and destructive joint diseases. Caused by a low amount of physical activities and a high amount of sedentary activities, primates in captivity often suffer from the same diseases of affluence than many humans do today. Like in humans, the most effective preventive measure to maintain health is to train fitness by increase the amount of physical activity. Under captive conditions most of the naturalistic stimuli for locomotor activity in primates are eliminated. Neither long distance travel nor escape from predators is necessary to survive. Moreover, distances to run or to leap are confined in an enclosure, particularly for larger primates. Therefore, adequate cage design is required to stimulate physical activity of the primate individuals under care.

A core concept in modern primate husbandry and management is environmental enrichment (e.g. Baker et al., 2006; Boere, 2001; Lutz and Novak, 2005; Reinhardt and Reinhardt, 2008; Wolfensohn and Honess, 2005). Its main aim is to enhance the psychological and social well-being of cap- tive primates and to prevent behavioural disorders such as stereotyped behaviours, cognitive deficits, and emotional disturbances. Within this conceptual framework, a variety of measures has been developed to stimulate exploratory and manipulatory activities of primates in captivity. The introduction of novel objects like toys or foraging devices, e.g. food dispensers with difficulty to obtain the food items are used to enrich the environment and to simulate foraging behaviour in the wild. While toy use and play is often confined to the youngsters and novel toys often lose their attraction within a few days, foraging devices enrich the daily activity of captive primates regardless of age and sex. Challenging food acquisition has been shown to substantially promote species-typical behaviour and to significantly increase the time-budget for food seeking and feeding (Lutz and Novak, 2005).

The training of physical fitness in order to improve strength and stamina of the primate musculoskeletal system yet plays a subordinate role in common enrichment concepts. In humans, exercise and mental health are closely linked (e.g. Chaouloff, 2008). Since humans share with other primates the neurophysiological basis for this linkage (e.g. the dopamine systems in the central nervous system), exercise will likely have antidepressant effects in primates as well and would have a very positive impact on the psychological wellbeing of captive individuals. Skeletal muscles have recently been identified as organ that produces and releases cytokines during its contractile activity (Pedersen and Febbraio, 2008). Cytokines are immunomodulating agents. Hence, exercise provokes an increase in the number of cytokines in the blood and thus may strengthen immune defence. In sum, exercise is an important factor in the promotion of health in humans and in other primates as well.

Practical implications for primate husbandry are that locomotor activity must be stimulated by an appropriate cage design. Especially the physically demanding locomotor modes such as running, leaping, and vertical climbing are analogues to exercise in captive primates, but these modes are often restricted by the size of the cage. An overall high density of branches and twigs may hinder fast progression, though it provides good climbing opportunities and easy access to all parts of the cage. Generally, tree trunks, branches, and rope swings should be arranged to give the primates a variety of textures, diameters and degrees of firmness. The diameters and orientation of the branches should be chosen with care according to species-specific substrate preferences in the wild. For callitrichids, surfaces should provide a good grip to the claws. Horizontal trunks with large diameters and as long as possible should be installed as runways; vertical trunks combined with meshes of ropes can be used as climbing scaffold. Reinhardt and Reinhardt (2008) reported that adult primates prefer fixed supports and show hardly any interest in movable structures such as swings or suspended barrels. Periodical rearrangements of the branches and tree trunks or an alternated access to an exercise or play cage 
are also sufficient measures to increase locomotor activity (Bryant et al., 1988; Hearn et al., 1978; Snowdon and Savage, 1989). For laboratory primates who are housed individually in small cages, periodic access to a larger exercise cage should be obligatory. For larger species such as baboons and macaques even weekly exercise session on a commercially available canine treadmill could be a useful measure to maintain physical fitness.

Beside all these measures to promote activity, primates in captivity also need their resting phases and places. High resting sites allowing the animals to retreat to a safe place should be basic furniture for every cage or enclosure.

Edited and reviewed by: E. W. Heymann

\section{References}

Arms A, Voges D, Fischer MS, Preuschoft H (2002) Arboreal locomotion in small New-World monkeys. Z Morph Anthropol 83:243-263

Arnason U, Gullberg A, Janke A (1998) Molecular timing of primate divergences as estimated by two nonprimate calibration points. J Mol Evol 47:718-727

Ashton EH, Oxnard CE (1964) Locomotor patterns in primates. Proc Zool Soc Lond 142:1-28

Baker KC, Weed JL, Crockett CM, Bloomsmith MA (2006) Survey of environmental enhancement programs for laboratory primates. Am J Primatol 69:377-394

Biewener AA (1983) Allometry of quadrupedal locomotion: the scaling of duty factor, bone curvature and limb orientation to body size. J Exp Biol 105:147-171

Bock WJ, von Wahlert G (1965) Adaptation and the form-function complex. Evolution 19:269-299

Boere V (2001) Environmental enrichment for neotropical primates in captivity. Ciência Rural, Santa Maria 31:543-551

Boinski S (1989) The positional behavior and substrate use of squirrel monkeys: ecological implications. J Hum Evol 18:659-677

Bryant CE, Rupniak NMJ, Iversen SD (1988) Effects of different environmental enrichment devices on cage stereotypies and autoaggression in captive cynomolgus monkeys. J Med Primatol 17:257-269

Cartmill M (1972) Arboreal adaptations and the origin of the order Primates. In: Tuttle RH (ed) The functional and evolutionary biology of primates. Chicago: Aldine-Atherton. p 97-122

Cartmill M (1974) Pads and claws in arboreal locomotion. In: Jenkins FA Jr (ed) Primate locomotion. New York: Academic Press. p 45-83

Cartmill M, Lemelin P, Schmitt D (2002) Support polygons and symmetrical gaits in mammals. Zool J Linn Soc 136:401-420

Chaouloff F (2008) Physical exercise and brain monoamines: a review. Acta Physiol Scand 137:1-13.

Charles-Dominique P, Martin RD (1970) Evolution of lorises and lemurs. Nature 227:257-260

Crompton RH (1984) Foraging, habitat structure, and locomotion in two species of Galago. In: Cant JG Rodman PC (eds) Adaptations for foraging in non-human primates. New York : Columbia University Press. p. 73-111

Cuvier G (1817) Le Règne Animal. Paris
Dagosto M (1995) Seasonal variation in positional behavior of Malagasy lemurs. Int J Primatol 16:807-833

Demes B, Günther MM (1989) Biomechanics and allometric scaling in primate locomotion and morphology. Folia Primatol 53:125-141

Demes B, Larson SG, Stern JT, Jungers WL, Biknevicius AR, Schmitt D (1994) The kinetics of primate quadrupedalism: "hindlimb drive" reconsidered. J Hum Evol 26:353-374

Demes B, Jungers WL, Fleagle JG Wunderlich RE Richmond BG Lemelin P (1996) Body size and leaping kinematics in Malagasy vertical clingers and leapers. J Hum Evol 31:367-388

Doran DM, Hunt KD (1994) Comparative locomotor behavior of chimpanzees and Bonobos: species and habitat differences. In: Wrangham RW McGrew WC de Waal FBM Heltne P (eds) Chimpanzee cultures. Cambridge: Harvard University Press. p 93-108

Doyle GA, Martin RD (1979) The study of prosimian behavior. New York: Academic Press

Dunbar DC (1989) Locomotor behavior of rhesus macaques (Macaca mulatta) on Cayo Santiago. P R Health Sci J 8:79-85

Erikson GE (1963) Brachiation in New World monkeys and anthropoid apes. Symp Zool Soc Lond 10:135-164

Fischer MS, Blickhan R (2006) The tri-segmented limbs of therian mammals: kinematics, dynamics, and self-stabilization. J Exp Zool 305:935-952

Fleagle JG (1999) Primate adaptation and evolution. San Diego: Academic Press

Fleagle JG, Mittermeier RA (1980) Locomotor behavior, body size, and comparative ecology of seven Surinam monkeys. Am J Phys Anthropol 52:301-314

Fleagle JG, Mittermeier RA, Skopec AL (1981) Differential habitat use by Cebus apella and Saimiri sciureus in central Surinam. Primates 22:361-367

Fontaine R (1990) Positional behavior in Saimiri boliviensis and Ateles geoffroyi. Am J Phys Anthropol 82:485-508

Ford SM (1980) Callitrichids as phyletic dwarfs, and the place of Callitrichidae in Platyrrhini. Primates 21:31-43

Gambaryan PP (1974) How mammals run: anatomical adaptations. New York: John Wiley

Garber PA (1991) A comparative study of positional behaviour in three species of tamarin monkeys. Primates 32:219-230

Gebo DL (1987) Locomotor diversity in prosimian primates. Am J Primatol 13:271-281

Gebo DL (1996) Climbing, brachiation, and terrestrial quadrupedalism: historical precursors of hominid bipedalism. Am J Phys Anthropol 101:55-92

Gebo DL (2004) A shrew-sized origin for primates. Yrbk Phys Anthropol 47:40-62

Gebo DL, Chapman CA (1995) Positional behavior in five sympatric Old World monkeys. Am J Phys Anthropol 97:49-76

Gebo DL, Dagosto M (1988) Foot anatomy, climbing, and the origin of the Indriidae. J Hum Evol 17:135-154

Gebo DL, Sargis EJ (1994) Terrestrial adaptations in the postcranial skeletons of guenons. Am J Phys Anthropol 93:341-371

Gould SJ (1966) Allometry and size in ontogeny and phylogeny. Biol Rev 41:587-640

Grand TI (1977) Body weight: its relation to tissue composition, segment distribution and motor function. I. Interspecific comparisons. Am J Phys Anthropol 47:241-248 
Grand TI (1984) Motion economy within the canopy: four strategies for mobility. In: Cant JG Rodman PC (eds) Adaptations for foraging in non-human primates. New York: Columbia University Press. p 54-72

Grzimek B (1988) Enzyklopädie der Säugetiere. (ed Kleienburg R) München: Kindler Verlag

Hanna JB, Schmitt D, Griffin TM (2008) The energetic cost of climbing in primates. Science 320:898

Hearn JP, Abbot DH, Chambers PC, Hodges JK, Lunn SF (1978) Use of the common marmoset, Callithrix jacchus, in reproductive research. Primates Med 10:40-49

Hershkovitz P (1977) Living New World monkeys (Platyrrhini): with an introduction to Primates. Vol. 1. Chicago: University of Chicago Press

Hildebrand M (1966) Analysis of the symmetrical gaits of tetrapods. Folia Biotheor 6:9-22

Hildebrand M (1967) Symmetrical gaits of primates. Am J Phys Anthropol 26:119-130

Hunt KD, Cant JGH, Gebo DL, Rose MD, Walker SE, Youlatos D (1996) Standardized description of primate locomotor and postural modes. Primates 37:363-387

Jolly CJ (1967) The evolution of the baboons. In: Vagtborg H (ed) The baboon in medical research. Vol. II. Austin: University of Texas Press. p 427-457

Jouffroy FK, Gasc JP (1974) A cineradiographical analysis of leaping in an African prosimian (Galago alleni). In: Jenkins FA Jr (ed) Primate locomotion. New York: Academic Press. p 117-142

Jouffroy FK, Lessertisseur J (1979) Relationships between limb morphology and locomotor adaptations among prosimians: an osteometric study. In: Morbeck ME Preuschoft H Gomberg N (eds) Environment, behavior, and morphology: dynamic interactions in primates. New York: Gustav Fischer. p 143-181

Jungers WL (1985) Body size and scaling of limb proportions in primates. In: Jungers WL (ed) Size and scaling in primate biology. New York: Plenum Press. p 345-381

Keith A (1923) Man's posture: its evolution and disorders. Brit Med J 1:451-454, 499-502, 545-548, 587-590, 624-626, 669-672

Kimura T, Okada M, Ishida H (1979) Kinesiological characteristics of primate walking: its significance in human walking. In: Morbeck ME Preuschoft H Gomberg N (eds) Environment, behavior, and morphology: dynamic interactions in primates. New York: Gustav Fischer. p 297-311

Larson SG (1998) Unique aspects of quadrupedal locomotion in non-human primates. In: Strasser E Fleagle JG Rosenberger A McHenry H (eds) Primate locomotion. recent advances. New York: Plenum Press. p 157-173

Larson SG, Stern JT Jr (1989) The role of propulsive muscles of the shoulder during quadrupedalism in vervet monkeys (Cercopithecus aethiops): implications for neural control of locomotion in primates. J Motor Behav 21:457-472

Lemelin P, Schmitt D, Cartmill M (2003) Footfall patterns and interlimb co-ordination in opossums (Family Didelphidae): evidence for the evolution of diagonal-sequence walking gaits in primates. J Zool, Lond 260:423-429

Lutz CK, Novak MA (2005) Environmental enrichment for nonhuman primates: theory and application. ILAR J 46:178-191

Martin RD (1972) Adaptive radiation and behaviour of the Malagasy lemurs. Phil Trans R Soc Lond 264:295-352
Martin RD (1973) A review of the behavior and ecology of the lesser mouse lemur (Microcebus murinus J. F. Miller, 1977). In: Michael RP Crook JH (eds) Comparative ecology and behavior of primates. London: Academic Press. p 1-68

Martin RD (1990) Primate origins and evolution. A phylogenetic reconstruction. Princeton, New Jersey: Princeton University Press

McGraw WS (1996) Cercopithecid locomotion, support use, and support availability in the Tai forest, Ivory Coast. Am J Phys Anthropol 100:507-522

Mollison T (1910.) Die Körperproportionen der Primaten. Gegenbaurs Morph Jb 42:79-304

Muybridge E (1957) Animals in motion. Brown LS (ed). New York: Dover (Originally published by Chapman \& Hall, London, 1899)

Napier JR Napier PH (1967) A handbook of living primates. London: Academic Press

Napier JR Walker AC (1967) Vertical clinging and leaping - a newly recognized category of locomotor behaviour of primates. Folia Primatol 6:204-219

Nowak RM (1999) Walker's mammals of the world. Sixth edition. Baltimore and London: The John Hopkins University Press

Pedersen BK, Febbraio MA (2008) Muscle as an endocrine organ: focus on muscle-derived interleukin-6. Physiol Rev 88:13791406

Peters RH (1986) The ecological implications of body size. Cambridge: Cambridge University Press

Preuschoft H, Demes B (1984) Biomechanics of brachiation. In: Preuschoft H Chivers DJ Brockelman WY Creel N (eds) The lesser apes. Evolutionary and behavioural biology. Edinburgh: Edinburgh University Press. p 96-118

Preuschoft H, Witte H, Fischer MS (1995). Locomotion in nocturnal prosimians. In: Alterman L Doyle GA Izard MK (eds) Creatures of the dark: the nocturnal prosimians. New York: Plenum Press. p 453-472

Prost JH (1965) A definitional system for the classification of primate locomotion. Am Anthrop 67:1198-1214

Raichlen DA, Shapiro LJ, Pontzer H, Sockol MD (2009) Understanding increased hind limb weight support in chimpanzees and the evolution of primate kinetics. Am J Phys Anthropol 138:395402

Ravosa MJ, Dagosto M (2007) Primate origins: adaptations and evolution. Developments in Primatology: Progress and Prospects. Tuttle R (series ed). New York: Springer

Reinhardt V, Reinhardt A (2008) Environmental enrichment and refinement for nonhuman primates kept in research laboratories. A photographic documentation and literature review. Washington: Animal Welfare Institute

Ripley S (1967) The leaping of langurs, a problem in the study of locomotor adaptations. Am J Phys Anthropol 26:149-170

Rollinson JMM, Martin RD (1981) Comparative aspects of primate locomotion, with special reference to arboreal cercopithecines. Symp Zool Soc Lond 48:377-427

Rose MD (1973) Quadrupedalism in primates. Primates 14:337357

Rose MD (1974) Postural adaptations in New and Old World monkeys. In: Jenkins FA Jr (ed) Primate locomotion. New York: Academic Press. p 201-222

Rose MD (1977) Positional behavior of olive baboons (Papio anubis) and its relationship to maintenance and social activities. Primates 18:59-116 
Rose MD (1979) Positional behavior in natural populations: some qualitative results of a field study of Colobus guereza and Cercopithecus aethiops. In: Morbeck ME Preuschoft H Gomberg N (eds) Environment, behavior, and morphology: dynamic interactions in primates. New York: Gustav Fischer. p 75-94

Rowe N (1996) The pictorial guide to the living primates. Charlestown, Rhode Island: Pogonias Press

Rylands AB (1993) Marmosets and tamarins: systematics, behavior, and ecology. Oxford: Oxford University Press

Schmidt M (2008) Forelimb proportions and kinematics: how are small primates different from other small mammals? J Exp Biol 211:3775-3789

Schmidt-Nielsen K (1975) Scaling in biology: the consequences of size. J Exp Zool 194:287-308.

Schmitt D (1999) Compliant walking in primates. J Zool, Lond 248:149-160

Snowdon CT, Savage A (1989) Psychological well-being of captive primates: general considerations and examples from callitrichids. In: Segal EF (ed) Housing, care and psychological wellbeing of captive and laboratory primates. Park Ridge: Noyes Publications. p 75-88

Stern JT, Oxnard CE (1973) Primate locomotion: some links with evolution and morphology. In: Hofer H Schultz AH Starck D (eds) Primatologia Vol 4. Basel: Karger. p 723-886

Sussman RW (1991) Primate origins and the evolution of angiosperms. Am J Primatol 23:209-223

Swedell L (2002) Ranging behavior, group size and behavioral flexibility in Ethiopian hamadryas baboons (Papio hamadryas hamadryas). Folia Primatol 73:95-103

Tavaré S, Marshall CR, Will O, Soligo C, Martin RD (2002) Using the fossil record to estimate the age of the last common ancestor of extant primates. Nature 416:726-729
Vilensky JA (1983) Gait characteristics of two macaques, with emphasis on relationships with speed. Am J of Phys Anthropol 61:255-265

Vilensky JA, Patrick MC (1985) Gait characteristics of two squirrel monkeys, with emphasis on relationships with speed and neural control. Am J of Phys Anthropol 68:429-444

Vilensky JA, Gankiewicz E, Townsend DW (1988). Effects of size on vervet (Cercopithecus aethiops) gait parameters: a crosssectional approach. Am J Phys Anthropol 76:463-480

Walker AC (1979) Prosimian locomotor behavior. In: Doyle GA Martin RD (eds) The study of prosimian behavior. New York: Academic Press. p 543-565

Walker SE (1998) Fine-grained differences within positional categories. A case study of Pithecia and Chiropotes. In: Strasser E Fleagle JG Rosenberger A McHenry H (eds) Primate locomotion. Recent advances. New York: Plenum Press. p 31-44

Ward SC, Sussman RW (1979) Correlates between locomotor anatomy and behavior in two sympatric species of Lemur. Am J Phys Anthropol 50:575-590

Wells JP, Turnquist JE (2001) Ontogeny of locomotion in rhesus macaques (Macaca mulatta): II. Postural and locomotor behavior and habitat use in a free-ranging colony. Am J Phys Anthropol 115:80-94

Witte H, Fischer MS, Schmidt M, Gruber S, Ludwig O, Hackert R, Schilling N, Voges D, Hoffmann H, Preuschoft H (2003) Human bipedality: mechanical preconditions and morphological adaptations. Cour Forsch-Inst Senckenberg 243:25-33

Wolfensohn S, Honess P (2005) Handbook of primate husbandry and welfare. Oxford: Blackwell Publishing 